\title{
Restless Leg Syndrome is Prevalent in Military Veterans with Post- Traumatic Stress Disorder and Sleep Disturbances
}

Faribrz Rezaeitalab ${ }^{1 *}$, Amir Rezaei Ardani ${ }^{2}$, Yalda Ravanshad ${ }^{3}$, Fariba Rezeetalab ${ }^{4}$, Saeideh Anvari Ardakani ${ }^{1}$, Mohammad Reza Sobhani ${ }^{1}$, Farahnaz Neurbakhsh ${ }^{1}$ and Hadi Abbasi ${ }^{1}$

${ }^{1}$ Department of Neurology, School of Medicine, Mashhad University of Medical Sciences, Mashhad, Iran

${ }^{2}$ Psychiatry and Behavioral Science Research Center, Mashhad University of Medical Sciences, Mashhad, Iran

${ }^{3}$ Clinical Research Development Center, Qaem Hospital, Mashhad University of Medical Sciences, Mashhad, Iran

${ }^{4}$ Lung Disease Research Center, Mashhad University of Medical Sciences, Mashhad, Iran

"Corresponding author: Faribrz Rezaeitalab, Associate Professor, Department of Neurology, School of Medicine, University of Medical Sciences, Mashhad, Iran, Tel: +985138413007; E-mail: Rezaitalabf@mums.ac.ir

Rec date: January 20, 2018; Acc date: February 16, 2018; Pub date: February 19, 2018

Copyright: ( 2018 Rezaeitalab F, et al. This is an open-access article distributed under the terms of the creative commons attribution license, which permits unrestricted use, distribution, and reproduction in any medium, provided the original author and source are credited.

\begin{abstract}
Introduction: While Restless leg syndrome (RLS) is a common sleep related movement disorder with a negative impact on sleep, quality of life and health, it may remain underdiagnosed for years. This study aims to evaluate RLS in military veterans with post-traumatic stress disorder (PTSD) suffering from sleep disturbances.

Material and methods: Thirty-One Iranian male military veterans diagnosed with PTSD entered this study. None of them had diabetes, Parkinson's disease and renal failure or were taking medications affecting RLS. Daytime sleepiness, anxiety and depression, RLS severity and the risk of obstructive sleep apnea (OSA) were assessed by standard questionnaires.

Results: The mean age was $51.6 \pm 6.1$ years. The most common complaint was difficulty falling asleep. Eight individuals (25.5\% of participants) had RLS. All of them had evidence of OSA based on the STOP-BANG questionnaire. The severity of RLS was not associate with sleepiness, depressive symptoms and body mass index (BMI), but with anxiety symptoms.
\end{abstract}

Conclusion: RLS should be taken into consideration in veterans with PTSD, particularly in those with sleep disturbances including insomnia, sleep related movements and sleep apnea.

Keywords: Insomnia; Military veterans; Nightmare; Obstructive sleep apnea; Post-traumatic stress disorder; Restless leg syndrome; Sleep related movements

\section{Introduction}

Combat veterans are at risk of health threats such as post-traumatic stress disorder (PTSD) [1], cardiovascular diseases [2], sleep related disorders or combinations of these conditions [3]. Sleep disturbances are frequently associated with PTSD. The most common symptoms are insomnia and nightmares [4-6]. Elevated frequencies of sleep-related movement disorders among PTSD veterans, like periodic limb movement of sleep (PLMs), have also been reported [3,7,8]. On the other hand, while restless leg syndrome (RLS) is a common sleep related movement disorder $[9,10]$, there are few studies assessing it in PTSD [11].

The International Restless Legs Syndrome Study Group (IRLSSG) defined four criteria to make a diagnosis of RLS: 1) an urge to move the legs due to some unpleasant sensations; 2) the unpleasant sensations are relieved by movement; 3 ) the symptoms become worse at night; and 4) the symptoms also become worse at rest [12]. Because of these nocturnal symptoms, sleep disturbance and insomnia are common presentations of RLS $[13,14]$. In addition, RLS may accompany other sleep disorders like obstructive sleep apnea and PLMs [13].
Accordingly, investigation for RLS is reasonable in any type of sleep disorders, which are significantly prevalent among PTSD veterans $[3,4]$. This study aimed to evaluate RLS presentation in an Iranian population of military veterans with PTSD. To best of our knowledge, the current study is the first one that focuses on the presentation and severity of RLS in veterans with PTSD.

\section{Materials and Methods}

This cross-sectional study was conducted on military veterans with sleep complaints attending the sleep laboratory of Ebn-e-Sina Hospital, Mashhad, Iran, between September 2014 and May 2015. The Ethics Committee of the Mashhad University of Medical Sciences (registered number 921368) approved the study. According to exclusion and inclusion criteria, 31 male military veterans were enrolled. A check list covering chief complaints and demographic data (including weight, height, and BMI) was obtained for each participant. The participants were interviewed and examined by a neurologist.

\section{Inclusion criteria}

1) Military veterans attending the Iraq-Iran (1981-1988), which approved by the Foundation of Martyrs and Veterans (a national organization in charge of veteran's affairs), with sleep complaints were 
Citation: Rezaeitalab F, Ardani AR, Ravanshad Y, Rezeetalab F, Ardakani SA, et al. (2018) Restless Leg Syndrome is Prevalent in Military Veterans with Post-Traumatic Stress Disorder and Sleep Disturbances. J Trauma Treat 7: 413. doi:10.4172/2167-1222.1000413

Page 2 of 5

enrolled. Out of the initially 87 people, 83 agreed to participate in this study

2) Considering exclusion criteria (see below), Forty-five persons were interviewed by a neurologist to evaluate for RLS based on IRLSSG criteria. 3) PTSD was confirmed in 31 participants by a psychiatrist.

\section{Exclusion criteria}

1) Concomitant Parkinson's disease, kidney failure and diabetes, which predispose or worsen RLS [15]. 2) Usage of medication or substances which affect the RLS symptoms during the previous fortnight. These include sedating antihistamines, Selective serotonin reuptake inhibitors (SSRIs), tricyclic antidepressants, antipsychotics and alcohol, which trigger or worsen RLS [16]; and gabapentin, pregabalin, clonazepam, dopa-agonists and opiates, which alleviate the symptoms [17].

\section{Tools}

The following questionnaires were applied for assessing related conditions: 1) The Epworth Sleepiness Scale (ESS) scoring was applied to evaluate daytime sleepiness. It includes eight items rated on a 4point scale (0-3), evaluates the chances of falling asleep while engaged in eight different diurnal situations [18]. 2) Beck Anxiety Inventory (BAI); and 3) Beck Depression Inventory (BDI): The BAI measures the severity of anxiety and is rated on a 3-point scale, with each question being scored as 0 to 3 [19]. The BDI assesses the severity of depression and is rated on a 4-point scale ranging from 0 to 3 based on the severity of each item. The cut-off scores are 0-9 (minimal depression), 10-18 (mild depression), 19-29 (moderate depression), and 30-63 (severe depression) [20]. 4) International Restless Legs Syndrome Rating Scale: it rates the severity of RLS symptoms by 10 questions scored as 0 to 4 scales [21]. 5) For screening obstructive sleep apnea (OSA), which is prevalent among military veterans [3], STOP-BANG questionnaire was applied. It consists of 8 yes/no questions. More than three positive response suggest the probability of OSA [22] The Validity and reliability of these questionnaire has been proven in the Iranian population [19-22].

\begin{tabular}{|l|l|l|l|l|}
\hline Variables & Minimum & Maximum & Mean & Std. Deviation \\
\hline BMI & 23.00 & 38.90 & 29.6290 & 4.23715 \\
\hline ESS & 1.00 & 24.00 & 9.8065 & 5.58223 \\
\hline AGE & 41.00 & 62.00 & 51.6129 & 6.16808 \\
\hline $\begin{array}{l}\text { RLS severity } \\
\text { score }\end{array}$ & .00 & 30.00 & 6.2258 & 7.89392 \\
\hline BAI & 10.00 & 34.00 & 20.3226 & 8.12152 \\
\hline BDI & 12.00 & 32.00 & 22.0645 & 5.35372 \\
\hline STOP-BANG & 2 & 8 & 5.44 & 2.345 \\
\hline $\begin{array}{l}\text { BMI: Body Mass Index; BAI: Beck Anxiety Inventory; BDI: Beck Depression } \\
\text { Inventory. ESS: Epworth Sleepiness Scale; RLS: Restless Leg Syndrome. }\end{array}$ \\
\hline
\end{tabular}

Table 1: Descriptive statistics.

\begin{tabular}{|l|l|l|}
\hline Variables & Frequency & Percentage \\
\hline Restless leg syndrome & 7 & 22.5 \\
\hline Abnormal movement during sleep & 4 & 12.9 \\
\hline Nightmare & 7 & 22.6 \\
\hline $\begin{array}{l}\text { Difficulty to falling asleep and/or } \\
\text { maintaining sleep }\end{array}$ & 10 & 32.3 \\
\hline Daytime sleepiness & 6 & 19.4 \\
\hline Morning headache & 3 & 9.7 \\
\hline Morning headache & 1 & 3.2 \\
\hline Total & 31 & 100.0 \\
\hline
\end{tabular}

Table 2: The frequency and percentage of chief complaints.

\begin{tabular}{|c|c|c|c|c|c|c|c|}
\hline \multicolumn{2}{|l|}{ Variables } & BMI & ESS & AGE & RLS & BAI & BDI \\
\hline \multicolumn{2}{|l|}{$\mathbf{N}$} & 31 & 31 & 31 & 31 & 31 & 31 \\
\hline \multirow[t]{3}{*}{ Normal Parametersa,b } & Mean & 29.6290 & 9.8065 & 51.6129 & 6.2258 & 20.3226 & 22.0645 \\
\hline & Std. Deviation & 4.23715 & 5.58223 & 6.16808 & 7.89392 & 8.12152 & 5.35372 \\
\hline & Absolute & 0.077 & 0.127 & 0.119 & 0.336 & 0.144 & 0.127 \\
\hline \multirow[t]{2}{*}{ Most Extreme Differences } & Positive & 0.069 & 0.122 & 0.119 & 0.336 & 0.144 & 0.127 \\
\hline & Negative & -0.077 & -0.127 & -0.099 & -0.215 & -0.118 & -0.112 \\
\hline \multicolumn{2}{|l|}{ Kolmogorov-Smirnov Z } & 0.430 & 0.706 & 0.664 & 1.871 & 0.803 & 0.708 \\
\hline \multicolumn{2}{|l|}{ Asymp. Sig. (2-tailed) } & 0.993 & 0.702 & 0.770 & 0.002 & 0.540 & 0.698 \\
\hline
\end{tabular}

Table 3: One-Sample Kolmogorov-Smirnov Test. 
Citation: Rezaeitalab F, Ardani AR, Ravanshad Y, Rezeetalab F, Ardakani SA, et al. (2018) Restless Leg Syndrome is Prevalent in Military Veterans with Post-Traumatic Stress Disorder and Sleep Disturbances. J Trauma Treat 7: 413. doi:10.4172/2167-1222.1000413

Page 3 of 5

\section{Results}

Thirty-One Iranian male military veterans with sleep complaints suffering from PTSD were evaluated for RLS and related problems. The mean age was $51.6 \pm 6.1$ and the mean elapsed time from combat exposure was $27.9 \pm 3.8$ years. The most common complaint was difficulty to falling asleep and/or maintaining sleep, following by nightmares. Descriptive statistics and chief complaints are demonstrated in Tables 1 and 2.
Seven participants $(22.5 \%$ of the participants) fulfilled the four criteria for RLS. The mean IRLSRS score for them was $17.7 \pm 9.9$ (in moderate range). Their chief complaints were nightmare (2 persons), difficulty to falling asleep and/or maintaining sleep (2), abnormal movement during sleep (2) and sleepiness (one of them). Regarding the correlation between the RLS severity score and the assessed parameters, only with BAI was significant (Tables 3-5).

\begin{tabular}{|c|c|c|c|c|c|c|}
\hline \multicolumn{2}{|c|}{ Variables } & \multirow{2}{*}{$\begin{array}{l}\text { BMI } \\
1\end{array}$} & \multirow{2}{*}{$\begin{array}{l}\text { ESS } \\
0.262\end{array}$} & \multirow{2}{*}{$\begin{array}{l}\text { AGE } \\
-0.144\end{array}$} & \multirow{2}{*}{$\begin{array}{l}\text { BAI } \\
-0.037\end{array}$} & \multirow{2}{*}{$\begin{array}{l}\text { BDI } \\
-0.211\end{array}$} \\
\hline BMI & Pearson Correlation & & & & & \\
\hline & Sig. (2-tailed) & - & 0.154 & 0.439 & 0.843 & 0.254 \\
\hline & $\mathrm{N}$ & 31 & 31 & 31 & 31 & 31 \\
\hline & Pearson Correlation & 0.262 & 1 & -0.136 & 0.061 & 0.018 \\
\hline \multirow[t]{3}{*}{ ESS } & Sig. (2-tailed) & 0.154 & - & 0.466 & 0.745 & 0.922 \\
\hline & $\mathrm{N}$ & 31 & 31 & 31 & 31 & 31 \\
\hline & Pearson Correlation & -0.144 & -0.136 & 1 & 0.067 & 0.195 \\
\hline \multirow[t]{3}{*}{ AGE } & Sig. (2-tailed) & 0.439 & 0.466 & - & 0.720 & 0.294 \\
\hline & $N$ & 31 & 31 & 31 & 31 & 31 \\
\hline & Pearson Correlation & -0.037 & 0.061 & 0.067 & 1 & $0.446^{*}$ \\
\hline \multirow[t]{3}{*}{ BAI } & Sig. (2-tailed) & 0.843 & 0.745 & 0.720 & - & 0.012 \\
\hline & $N$ & 31 & 31 & 31 & 31 & 31 \\
\hline & Pearson Correlation & -0.211 & 0.018 & 0.195 & $0.446^{*}$ & 1 \\
\hline \multirow[t]{2}{*}{ BDI } & Sig. (2-tailed) & 0.254 & 0.922 & 0.294 & 0.012 & - \\
\hline & $\mathrm{N}$ & 31 & 31 & 31 & 31 & 31 \\
\hline
\end{tabular}

Table 4: Correlations.

\begin{tabular}{|l|l|l|}
\hline Variables & With RLS & Without RLS \\
\hline Number & 7 & 24 \\
\hline Mean BMI & 28.98 & 29.81 \\
\hline Mean ESS & 9.11 & 9.90 \\
\hline Mean BAI & 24.72 & 19.22 \\
\hline Mean BDI & 23.1 & 21.97 \\
\hline Mean Age & 50.88 & 51.79 \\
\hline
\end{tabular}

\section{Discussion}

Seven participants out of 31 male military veterans with PTSD suffering from sleep related problems had RLS in our study. Predisposing conditions including renal failure, diabetes and medications had been excluded. Meanwhile, it should be emphasized that such conditions which worsen RLS are prevalent among chronic PTSD veterans in particular diabetes [23] and usage of antidepressants [24].

RLS is a common disorder with estimated prevalence between 5 to $10 \%$ in western countries [25] and with lower range in Asian countries [11]. Higher prevalence is reported in certain conditions such as renal failure (more than 25\%) [26], pregnancy (up to 21\%) [27] and neuropathies (around 10\%) [28]. The relationships between RLS and cardiovascular disorders and death have been demonstrated in several studies [29-31]. Also, RLS has been shown to be associated with depression [32]. As such conditions are common comorbidities in combat veterans with PTSD [3], investigation for symptoms of RLS in these individuals may be of important value. 
The high presence of RLS in our subjects (22.5\%) suggest that PTSD in veterans may be associated with RLS. Till now, there is a paucity of research studies that evaluate the association of RLS and PTSD [11,16]. In a Korean study conducted on general population, the lifetime diagnosis of PTSD was associated with RLS [11]. While the explanation for this co-occurrence has remained uncertain, sleep disturbance is the intersections of the two conditions [16]. Insomnia, nightmares, sleep related movement and daytime sleepiness are frequently reported symptoms by PTSD veterans [33]. In our study, while all of subjects had a complaint of sleep disturbances and depressive and anxiety symptoms, there was statistically significant association between RLS scores and anxiety severity representing by BAI. RLS score was not related with other parameters.

Also, all of our RLS patients had scores of STOP-BANG of more than 4. RLS has been shown to be prevalent in sleep-related breathing disorders including OSA [13]. On the other hand, OSA is a common condition in military veterans [3]. Altogether, a detailed history is essential in management of PTSD of military veterans with sleep problems. While negative effects of RLS on mental and physical health have been proven in a large body of studies, it may remain underdiagnoses, because the symptoms overlap with other sensory and motor disorders [34].

There are studies using polysomnography that showed high index of periodic limb movements of sleep (PLMS), a sleep related movement disordering PTSD veterans $[3,8,35]$. As PLMS are the most important objective findings of RLS, it can be expected that RLS is prevalent in these patients. To best of our knowledge, the current study for the first time shows high frequency of RLS among military veterans suffering from PTSD and sleep disturbances. However, small sample size is a limitation of our study. Further studies with larger samples and evaluate RLS in PTSD and Non-PTSD veterans are recommended.

\section{Conclusion}

Evaluation for RLS in veterans with PTSD is highly recommended, in particular at the presence of sleep related complaints including insomnia, movements during sleep, daytime sleepiness and nightmare.

\section{Acknowledgements}

We would like to appreciate the Foundation of Martyrs and Veterans of Iran, Khorasan Rzavi Province for their cooperation with this study.

\section{Conflicts of interest}

The authors declare that they no conflict of interest.

\section{References}

1. Ahmadi K, Hazrati M, Ahmadizadeh M, Noohi S (2015) REM desensitization as a new therapeutic method for post-traumatic stress disorder: a randomized controlled trial. Acta Med Indones 47: 111-119.

2. Kibler JL, Tursich M, Ma Malcom L, Greeanbarg RM (2014) Metabolic, autonomic and immune markers for cardiovascular disease in posttraumatic stress disorder. World J Cardiol 6: 455-461.

3. Rezaeitalab F, Mokhber N, Ravanshad Y, Saberi S, Rezaeetalab F (2018) Different polysomnographic patterns in military veterans with obstructive sleep apnea in those with and without post-traumatic stress disorder. Sleep Breath 1-6.
4. Lavie P (2001) Sleep disturbances in the wake of traumatic events. N Engl J Med 345: 1825-1832.

5. Pigeon WR, Gallegos AM (2015) Posttraumatic stress disorder and sleep. Sleep Med Clin 10: 41-48.

6. Lind MJ, Brown E, Farrell-Carnahan L, Brown RC, Hawn S, et al. (2017) Sleep disturbances in OEF/OIF/OND veterans: Associations with PTSD, personality, and coping. J Clin Sleep Med 13: 291-299.

7. Mysliwiec V, Brock MS, Creamer JL, O'Reilly BM, Germain A, et al (2017) Trauma associated sleep disorder: A parasomnia induced by trauma. Sleep Med Rev 37: 94-104.

8. Germain A, Nielsen TA (2003) Sleep pathophysiology in posttraumatic stress disorder and idiopathic nightmare sufferers. Biol Psychiatry 54: 1092-1098.

9. Trotti LM (2017) Restless legs syndrome and sleep-related movement disorders. Continuum (Minneap Minn) 23: 1005-1016.

10. American Academy of Sleep Medicine (2014) International classification of sleep disorders, (3rd edn) American Academy of Sleep Medicine, Darien.

11. Cho SJ, Hong JP, Hahm BJ, Jeon HJ, Chang SM, et al. (2009) Restless legs syndrome in a community sample of Korean adults: prevalence, impact on quality of life, and association with DSM-IV psychiatric disorders. Sleep 32: 1069-1076.

12. Allen RP, Picchietti D, Hening WA, Trenkwalder C, Walters AS, et al. (2003) Restless legs syndrome: Diagnostic criteria, special considerations, and epidemiology. A report from the restless legs syndrome diagnosis and epidemiology workshop at the National Institutes of Health. Sleep Med 4: 101-119.

13. Roux FJ (2013) Restless legs syndrome: impact on sleep-related breathing disorders. Respirology 18: 238-245.

14. Liu X, Chen H, Liu ZZ, Jia CX (2018) Insomnia and psychopathological features associated with restless legs syndrome in Chinese adolescents. J Clin Psychiatry 79: 16m11358.

15. Trenkwalder C, Paulus W, Walters AS (2005) The restless legs syndrome. Lancet Neurol 4: 465-475.

16. Picchietti D, Winkelman JW (2005) Restless legs syndrome, periodic limb movements in sleep, and depression. Sleep 28: 891-898.

17. Wijemanne S, Ondo W (2017) Restless legs syndrome: Clinical features, diagnosis and a practical approach to management. Pract Neurol 17: 444-452.

18. Haghighi KS, Montazeri A, Mehrizi AK, Aminian O, Golkhandan AR, et al. (2013) The Epworth sleepiness scale: Translation and validation study of the Iranian version. Sleep Breath 17: 419-426.

19. Kaviani H, Mousavi AS (2005) Psychometric properties of the Persian version of Beck anxiety inventory. Tehran Univ Med J 65: 136-140.

20. Mental Health Research Center, Tehran Psychiatric Institute, Iran (2010) Beck depression inventory scoring.

21. Molahosseini SH, Mohammadzadeh SH, Kamali P, Tavakkoli Shooshtari M (2005) Frequency of sleep disorder and restless legs syndrome in patients referring to hemodialysis units in university hospitals in Tehran in 2003. Med Sci J Islamic Azad Univ Tehran. Med Branch 15: 27-30.

22. Sadeghniiat-Haghighi K, Montazeri A, Khajeh-Mehrizi A, Ghajarzadeh M, Alemohammad ZB, et al. (2015) The STOP-BANG questionnaire: reliability and validity of the Persian version in sleep clinic population. Qual Life Res 24: 2025-2030.

23. MacNamara A, Rabinak CA, Kennedy AE, Fitzgerald DA, Liberzon I, et al. (2016) Emotion regulatory brain function and SSRI treatment in PTSD: Neural correlates and predictors of change. Neuropsychopharmacol 41: 611-618.

24. Tison F, Crochard A, Léger D, Bouée S, Lainey E, et al. (2005) Epidemiology of restless legs syndrome in French adults: a nationwide survey: the INSTANT Study. Neurology 65: 239-246.

25. Lin Z, Zhao C, Luo Q, Xia X, Yu X, et al. (2016) Prevalence of restless legs syndrome in chronic kidney disease: a systematic review and metaanalysis of observational studies. Ren Fail 38: 1335-1346. 
Citation: Rezaeitalab F, Ardani AR, Ravanshad Y, Rezeetalab F, Ardakani SA, et al. (2018) Restless Leg Syndrome is Prevalent in Military Veterans with Post-Traumatic Stress Disorder and Sleep Disturbances. J Trauma Treat 7: 413. doi:10.4172/2167-1222.1000413

Page 5 of 5

26. Chen SJ, Shi L, Bao YP, Sun YK, Lin X, et al. (2017) Prevalence of restless legs syndrome during pregnancy: A systematic review and meta-analysis. Sleep Med Rev S1087-0792.

27. Harashima S, Nishimura A, Osugi T, Wang Y, Liu Y, et al. (2016) Restless legs syndrome in patients with type 2 diabetes: effectiveness of pramipexole therapy. BMJ Support Palliat Care 6: 89-93.

28. Li Y, Li Y, Winkelman JW, Walters AS, Han J, et al. (2018) Prospective study of restless legs syndrome and total and cardiovascular mortality among women. Neurology 90: 135-141.

29. Katsanos AH, Kosmidou M, Konitsiotis S, Tsivgoulis G, Fiolaki A, et al (2018) Restless legs syndrome and cerebrovascular/cardiovascular events: Systematic review and meta-analysis. Acta Neurol Scand 137: 142-148.

30. Kendzerska T, Kamra M, Murray BJ, Boulos MI (2017) Incident cardiovascular events and death in individuals with restless legs syndrome or periodic limb movements in sleep: A systematic review. Sleep.
31. Koo BB, Blackwell T, Lee HB, Stone KL, Louis ED, et al. (2016) Restless legs syndrome and depression: effect mediation by disturbed sleep and periodic limb movements. Am J Geriatr Psychiatry 24: 1105-1116.

32. Brown WJ, Wilkerson AK, Milanak ME, Tuerk PW, Uhde TW, et al. (2017) An examination of sleep quality in veterans with a dual diagnosis of PTSD and severe mental illness. Psychiatry Res 247: 15-20.

33. Tipton PW, Wszołek ZK (2017) Restless legs syndrome and nocturnal leg cramps: a review and guide to diagnosis and treatment. Pol Arch Intern Med 127: 865-872.

34. Buljan R, Hrabrić K, Jukić V, Bisko A (2008) Disturbed sleep in war veterans according to overnight polysomnography. Lijec Vjesn 130: 101-103.

35. Ferri R, Koo BB, Picchietti DL, Fulda S (2017) Periodic leg movements during sleep: Phenotype, neurophysiology, and clinical significance. Sleep Med 31: 29-38. 